\title{
Correction to: Redox Modulation at Work: Natural Phytoprotective Polysulfanes From Alliums Based on Redox-Active Sulfur
}

\author{
Awais Anwar ${ }^{1,2} \cdot$ Emma Gould $^{2} \cdot$ Ryan Tinson $^{2} \cdot$ Javaid Iqbal $^{3} \cdot$ Chris Hamilton $^{2}$
}

Published online: 3 June 2019

(C) The Author(s) 2019

Correction to: Current Pharmacology Reports (2018)

4(5):397-407

https://doi.org/10.1007/s40495-018-0153-2

The original version of this article unfortunately contained a mistake. The PDF version and the online version have discrepancies in the affiliations of the authors. The correct affiliations are given below.

Open Access This article is distributed under the terms of the Creative Commons Attribution 4.0 International License (http:// creativecommons.org/licenses/by/4.0/), which permits unrestricted use, distribution, and reproduction in any medium, provided you give appropriate credit to the original author(s) and the source, provide a link to the Creative Commons license, and indicate if changes were made.

Publisher's Note Springer Nature remains neutral with regard to jurisdictional claims in published maps and institutional affiliations.

The online version of the original article can be found at https://oi.org/ 10.1007/s40495-018-0153-2

Awais Anwar

awais@ecospray.com

Ecospray Limited, Grange Farm, Hilborough, Thetford, Norfolk IP26 5BT, UK

2 School of Pharmacy, University of East Anglia, Norwich Research Park, Norwich NR4 7TJ, UK

3 Department of Plant Protection, College of Food and Agriculture Sciences, King Saud University, Riyadh, Saudi Arabia 